\title{
Relative role of horizontal and vertical processes in the physical mechanism of wintertime Arctic amplification
}

\author{
Ji-Young Kim ${ }^{1} \cdot$ Kwang-Yul Kim ${ }^{1}$
}

Received: 5 July 2018 / Accepted: 13 October 2018 / Published online: 19 October 2018

(C) The Author(s) 2018

\begin{abstract}
The physical mechanism of Arctic amplification is still controversial. Specifically, relative role of vertical processes resulting from the reduction of sea ice in the Barents-Kara Seas is not clearly understood in comparison with the horizontal heat and moisture advection. Energy and moisture budgets are analyzed over the region of sea ice reduction in order to delineate the relative roles of horizontal and vertical processes. A detailed analysis of energy and moisture budgets in the atmospheric column indicates that both the vertical source from the release of heat flux and moisture due to sea ice reduction and the horizontal advection of heat and moisture are essential for explaining the variation of temperature and specific humidity over the Barents-Kara Seas. The vertical flux term explains a slightly larger fraction of the mean increase in temperature and specific humidity, while the horizontal advection is a major source of variability in temperature and specific humidity in the atmospheric column.
\end{abstract}

\section{Introduction}

In recent decades, Arctic warming has been accelerating in the lower troposphere during the cold season (Serreze et al. 2009; Screen and Simmonds 2010a; Screen et al. 2013). In particular, sea ice reduction over the Barents-Kara Seas and corresponding lower tropospheric warming during winter have drawn much interest in recent years (Petoukhov and Semenov 2010; Sorokina et al. 2016; Yang et al. 2016; Ruggieri et al. 2017). The Barents-Kara Seas are the only region in the Arctic Ocean, where wintertime sea ice reduction is conspicuous; other areas of the Arctic Ocean do not exhibit significant loss of sea ice during the winter (Kim et al. 2016). The September (minimum) sea ice extent over the Arctic Ocean (Serreze and Stroeve 2015) as well as winter (DJF) sea ice cover over the Barents-Kara Seas (Kim et al. 2016; see also Fig. S1) have dwindled by 50\% during the past 40 years and it seems to be continuing at a faster rate.

Electronic supplementary material The online version of this article (https://doi.org/10.1007/s00382-018-4499-2) contains supplementary material, which is available to authorized users.

Kwang-Yul Kim

kwang56@snu.ac.kr

1 School of Earth and Environmental Sciences, Seoul National University, 1 Gwanak-ro, Gwanak-gu, Seoul 08826, Republic of Korea
At the same time, lower tropospheric winter temperature has risen by $\sim 2 \mathrm{~K}$ during the same time interval (Johannessen et al. 2016; Kim et al. 2016).

Several physical mechanisms are proposed to explain the wintertime sea ice reduction and the lower tropospheric warming over the Barents-Kara Seas. The most widely accepted mechanism is the "insulation feedback" (Overland et al. 2011; Burt et al. 2016; Kim et al. 2016). The lower tropospheric warming is due to turbulent heat flux released from the open sea surface, which remains to be free of ice in winter (Screen and Simmonds 2010a, b; Deser et al. 2010; Overland et al. 2011; Serreze and Barry 2011; Cohen et al. 2014; Kim et al. 2016). According to this proposed mechanism, increased reception of insolation through the sea surface exposed to air in summer keeps the sea surface warmer and the stored energy in summer is released in fall and early winter making the atmosphere warmer.

Another mechanism is the "water vapor feedback" (Francis and Hunter 2006; Sedlar et al. 2011; Park et al. 2015a, b). As warming increases, water vapor content in the atmospheric column increases, leading to an amplified greenhouse effect. Upward infrared radiation (IR) is trapped more in the atmospheric column, resulting in warming of the atmospheric column. Increase in atmospheric water vapor may be due to an increase in both local evaporation and transport from lower latitudes (Jakobson and Vihma 2010; Kurita 2011). 
Most studies agree that increasing downward IR due to atmospheric warming is the essential factor for the continuing reduction of sea ice. The two mechanisms addressed above are instrumental in explaining the relationship between the sea ice reduction in the Barents-Kara Seas and the lower tropospheric warming over the region of sea ice reduction. Meanwhile, there are different explanations for the cause-and-effect relationship between the sea ice reduction and the lower tropospheric warming over the BarentsKara Seas. Park et al. (2015a) suggested that the increase in downward IR is primarily due to horizontal advection of water vapor and heat energy into the Arctic from lower latitudes, rather than evaporation from the Arctic Ocean. Park et al. (2015b) suggest that northward flux of moisture into the Arctic is connected with enhanced convection over the tropical Indian and western Pacific Ocean, and that this northward flux of moisture increases downward IR.

Burt et al. (2016), on the other hand, showed that the simulated moistening of the Arctic atmosphere during winter is primarily due to an increase in surface evaporation rather than poleward moisture transport. Kurita (2011) analyzed the source region of Arctic water vapor during the ice-growth season and reported that local moisture source is dominant during late fall and early winter but moisture transport from lower latitudes becomes more important than local source after early winter.

As described above, relative role of vertical processes resulting from the reduction of sea ice in the Barents-Kara seas to horizontal advective processes is not yet clearly understood. In the present study, energy and moisture budgets are analyzed over the region of sea ice reduction in order to delineate the relative roles of horizontal and vertical processes. Moisture budget equation is used to compare the horizontal moisture advection term and vertical source of evaporation minus precipitation in explaining specific humidity change in the atmospheric column. Thermal energy budget equation is also used to assess the relative importance of horizontal heat advection and vertical source of energy from the release of turbulent heat fluxes and radiation trapped in the atmospheric column.

\section{Data and method of analysis}

\subsection{Data}

ERA-Interim daily surface and pressure-level variables at $1.5^{\circ} \times 1.5^{\circ}$ resolution are used for the period of 1979-2017 (Dee et al. 2011). The domain of analysis is the Arctic region (north of $60^{\circ} \mathrm{N}$ ) during winter (Dec. 1-Feb. 28; 90 days) to focus on the mechanisms of wintertime Arctic sea ice reduction. We focus on winter (DJF), since it is the season of maximum sea ice reduction and Arctic warming over the Barents-Kara Seas (Kim et al. 2016).

\subsection{CSEOF analysis}

Cyclostationary empirical orthogonal function (CSEOF) analysis is conducted to isolate the mode associated with the wintertime sea ice reduction in the Barents-Kara Seas (Kim et al. 1996, 2015; Kim and North 1997). Daily sea ice concentration is written in the form:

$T(r, t)=\sum_{n} B_{n}(r, t) T_{n}(t), \quad B_{n}(r, t)=B_{n}(r, t+d)$,

where $B_{n}(r, t)$ are the cyclostationary loading vectors (CSLV), $T_{n}(t)$ are the principal component (PC) time series, and $d=90$ days is the nested period. Thus, each loading vector consists of 90 spatial patterns describing evolution of sea ice during winter (DJF). Each CSLV is modulated on a longer term by corresponding amplitude (PC) time series. Figure 1 shows the winter-averaged CSLV and PC time series for the first CSEOF mode. Judging from the CSLV (Fig. 1a) and PC time series (Fig. 1c), this mode represents the accelerated reduction of sea ice over the Barents-Kara Seas (see also Fig. S1). According to Fig. 1a, c, sea ice concentration has decreased by $\sim 50 \%$ over the Barents-Kara Seas since 1979.

In order to extract evolution of other variables to be physically consistent with the evolution of sea ice concentration in Fig. 1, regression analysis is conducted in CSEOF space. The sea ice concentration is called the "target" variable and other variables are called the "predictor" variables. This step is essential to make the evolution of all predictor variables to be physically consistent with that of target variable (sea ice concentration). First, CSEOF analysis is conducted on a predictor variable (say, $2 \mathrm{~m}$ air temperature):

$P(r, t)=\sum_{n} C_{n}(r, t) P_{n}(t)$,

where $C_{n}(r, t)$ and $P_{n}(t)$ are the CSLV and PC time series of the predictor variable. In general, there is no one-to-one correspondence between two sets of CSLVs in (1) and (2), since $T_{n}(t) \neq P_{n}(t)$. In order to establish a one-to-one correspondence between the two sets of CSEOF modes, regression analysis is conducted in CSEOF space:

$T_{n}(t)=\sum_{m=1}^{M} \alpha_{m}^{(n)} P_{m}(t)+\varepsilon^{(n)}(t)$,

$C_{n}^{(r e g)}(r, t)=\sum_{m=1}^{M} \alpha_{m}^{(n)} C_{m}(r, t)$,

where $\left\{\alpha_{m}^{(n)}\right\}$ are the regression coefficients and $\varepsilon^{(n)}(t)$ is the regression error time series for the $n$th mode, and $M(=20$ in 

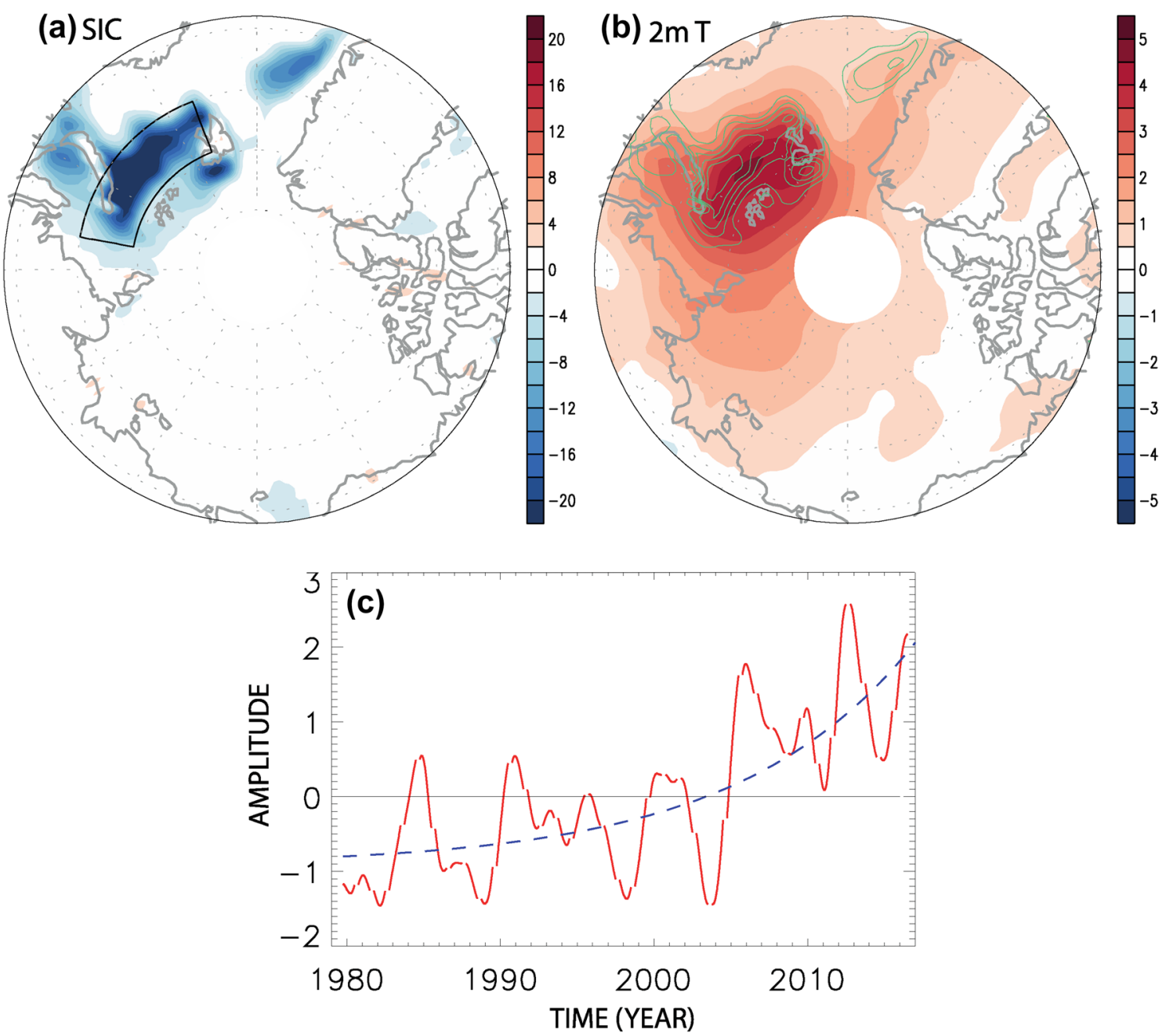

Fig. 1 Winter-averaged pattern of a sea ice concentration, b $2 \mathrm{~m}$ air temperature, and corresponding PC (amplitude) time series associated with Arctic amplification. The boxed area $\left(21^{\circ}-79.5^{\circ} \mathrm{E}, 75^{\circ}-\right.$

$79.5^{\circ} \mathrm{N}$ ) in a represents the region of significant sea ice reduction in the Barents-Kara Seas. The contour lines (at 5\% interval) in $\mathbf{b}$ denote the sea ice concentration in a

the present study) is the number of predictor modes used for regression. Then, the predictor variable can be rewritten as

$P(r, t)=\sum_{n} C_{n}^{(r e g)}(r, t) T_{n}(t)$.

Note that each loading vector $C_{n}^{(\text {reg })}(r, t)$ of the predictor variable $P(r, t)$ is now associated with the PC time series of the target variable $T_{n}(t)$. For example, Fig. $1 \mathrm{~b}$ is the winteraveraged regressed loading vector of surface $(2 \mathrm{~m})$ air temperature (SAT). The two loading vectors in Fig. 1 share the same PC time series in Fig. 1c.

As a result of regression analysis on all predictor variables, the entire dataset can be written as

$\operatorname{Data}(r, t)=\sum_{n}\left\{B_{n}(r, t), C_{n}^{\{r e g\}}(r, t), \ldots, Z_{n}^{\{r e g\}}(r, t)\right\} T_{n}(t)$.
The terms in curly braces represent CSLVs from different variables and they all are governed by the PC time series of the target variable $\left\{T_{n}(t)\right\}$. The terms in curly braces are considered physically and dynamically consistent with each other.

\subsection{Energy budget equations}

In order to assess the relative roles of horizontal and vertical processes in the Arctic warming, let us first consider the following moisture conservation equation in pressure coordinates:

$\frac{\partial q}{\partial t}=-\vec{u} \cdot \nabla q+S=-\vec{u} \cdot \nabla_{p} q-\omega \frac{\partial q}{\partial p}+S$,

where $q$ is specific humidity, $\vec{u}$ is velocity, $p$ is pressure, $\omega \equiv D p / D t$ is "omega" vertical velocity, $S$ is moisture source, and the subscript $p$ denotes that differentiation is on 
a constant pressure surface. Multiplying (7) by $\rho_{a}$ and integrating the resulting equation with respect to $z$, we obtain

$\frac{\partial}{\partial t} \int_{0}^{z} \rho_{a} q d z=-\int_{0}^{z} \rho_{a} \vec{u} \cdot \nabla_{p} q d z-\int_{0}^{z} \rho_{a} \omega \frac{\partial q}{\partial p} d z+\rho_{w}(E-P)$,

where $\rho_{a}$ is density of air, $\rho_{w}$ is density of water, and the moisture source is equal to evaporation $(E)$ minus precipitation $(P)$. Equation $(8)$ can be rewritten as

$\int_{p}^{p_{0}} q d p=\left[-\int_{p}^{p_{0}} \vec{u} \cdot \nabla_{p} q d p-\int_{p}^{p_{0}} \omega \frac{\partial q}{\partial p} d p+\rho_{w} g(E-P)\right] \Delta t$,

where $g$ is gravitational acceleration, $p=p(z)$, and $p_{0}$ is surface pressure which is assumed to be $1000 \mathrm{hPa}$ here. The right-hand side is the total amount of moisture change due respectively to horizontal advection, vertical convection and net evaporation (evaporation minus precipitation) during a time interval $\Delta t$, which is 1 day in the present study. The left-hand side, then, is the amount of moisture increase (anomalous specific humidity) in the atmospheric column.

Let us now consider the thermal energy equation:

$\frac{\partial T}{\partial t}+\vec{u} \cdot \nabla_{p} T-S_{p} \omega=\frac{J}{c_{p}}$,

where the stability parameter $S_{p}$ is defined by

$S_{p}=\frac{R T}{c_{p} p}-\frac{\partial T}{\partial p}=-\frac{T}{\theta} \frac{\partial \theta}{\partial p}$.

Here $c_{p}$ is the specific heat at constant pressure, $R$ is the specific gas constant, $\theta$ is potential temperature, and $J$ is diabatic forcing (heat flux per unit volume). If we integrate (10) with respect to $p$, we have

$\int_{p}^{p_{0}} T d p=\left[-\int_{p}^{p_{0}} \vec{u} \cdot \nabla_{p} T d p+\int_{p}^{p_{0}} S_{p} \omega d p+\int_{p}^{p_{0}} \frac{J}{c_{p}} d p\right] \Delta t$.

The diabatic forcing includes latent and sensible heat flux at the surface as well as radiative forcing in the atmospheric column produced by the increased specific humidity. Thus, we assume that the last term can be written as

$\int_{0}^{p_{0}} \frac{J}{c_{p}} d p=\frac{g}{c_{p}}\left(F_{S}+F_{L}+F_{R}\right)$,

where $F_{S}, F_{L}$ and $F_{R}$ are sensible heat flux, latent heat flux, and radiative flux, respectively. The radiative flux in the entire atmospheric column is determined by the net radiation trapped in the atmospheric column, i.e.,

$F_{R}=F_{\text {surface }}-F_{\mathrm{TOA}}$.

Regression analysis is conducted in CSEOF space on all variables in (9) and (12) so that their spatio-temporal evolutions become consistent with the evolution of sea ice in Fig. 1. Then, the regressed CSLVs are used to evaluate each term in (9) and (12) in order to assess quantitatively the importance of each term in explaining the changes in temperature and specific humidity in association with the sea ice reduction over the Barents-Kara Seas.

\section{Results of analysis and discussion}

\subsection{Sea ice reduction and atmospheric warming}

As can be seen in Fig. 1b, Arctic warming is observed close to the region of sea ice reduction in the Barents-Kara Seas; both the sea ice reduction and surface air warming are accelerating rapidly in the record (Fig. 1c). The atmospheric warming is strongly confined to the lower troposphere over the region of sea ice reduction (Fig. 2a, b) and the increased specific humidity is also evident (Fig. 2c, d). Calculation based on the Clausius-Clapeyron relationship (Iribarne and Godson 1981; North and Erukhimova 2009) shows that the increased saturation specific humidity owing to the increased air temperature is commensurate in magnitude with the increased specific humidity. Figure 2 shows that the winteraveraged patterns of specific humidity are similar to those of air temperature and saturation specific humidity. Note that significant increase in temperature and specific humidity is confined to lower troposphere. As a result of sea ice reduction, turbulent heat flux is increased (Kim et al. 2016). Due to an increased exposition of warmer sea surface, upward longwave radiation increases, whereas downward longwave radiation also increases due to increased lower tropospheric temperature (Kim et al. 2016).

\subsection{Moisture budget}

The spatial and temporal patterns of specific humidity, horizontal advection and vertical source terms in (9), in association with the sea ice reduction in Fig. 1, are summarized in Figs. 3 and 4. The winter-averaged regressed pattern of lower-tropospheric (1000-850 hPa) specific humidity (Fig. 3a) is depicted together with the contributions from the horizontal advection (Fig. 3b), source (evaporation minus precipitation; Fig. 3c), and the sum of all contributions [right-hand side of (9); Fig. 3d]. The contribution from the vertical convection of moisture is very small in the lower troposphere (figure not shown). As can be seen, the magnitude of moistening from the source term is comparatively larger than the horizontal advection of moisture in association with Arctic amplification. Both the local source (net evaporation) and the horizontal advection of moisture seem essential in explaining the increased specific humidity in the atmospheric column. 


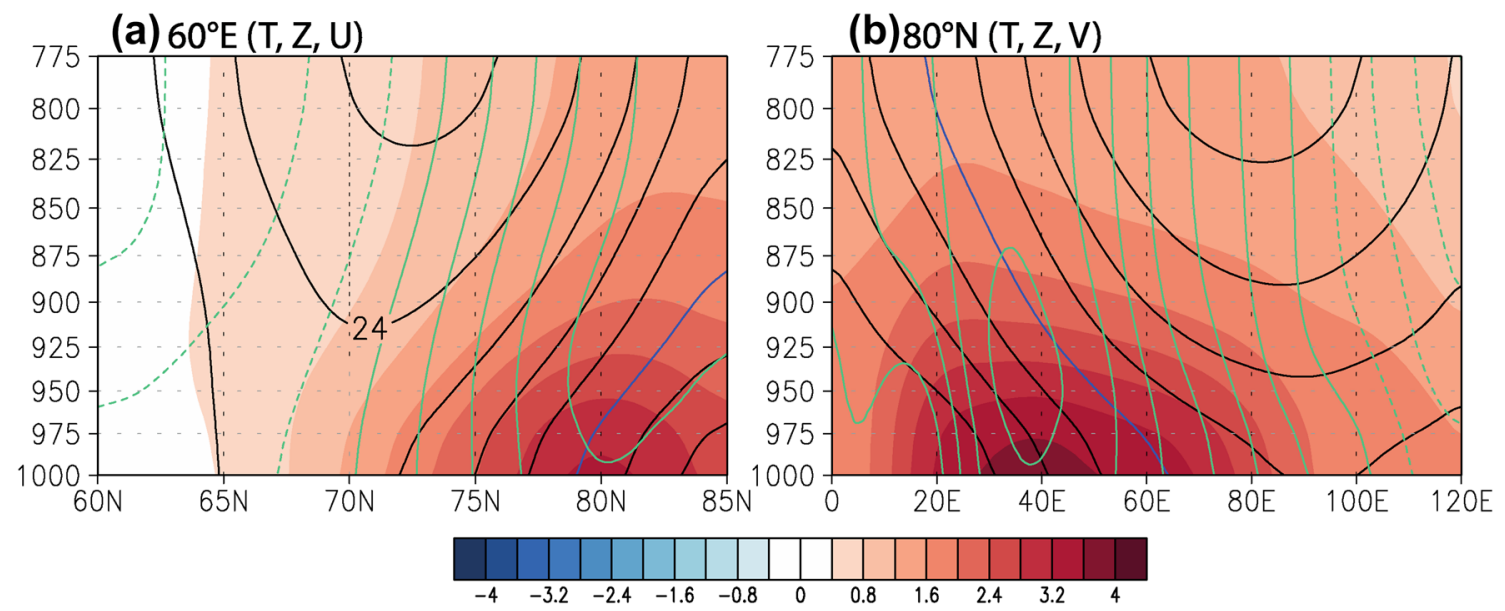

(c) $60^{\circ} \mathrm{E}\left(\mathrm{q}, \mathrm{q}_{\mathrm{s}}\right)$

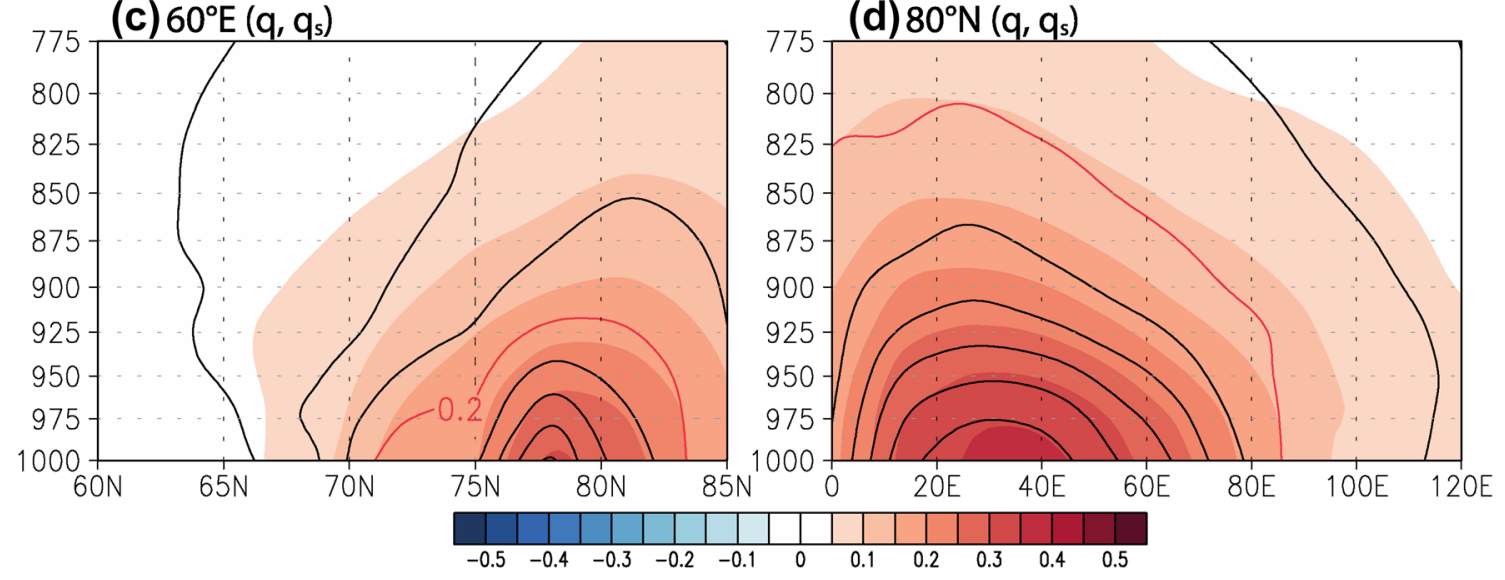

Fig. 2 a, b The vertical pattern of winter-averaged temperature (shade), geopotential (black contour; $3 \mathrm{~m}^{2} \mathrm{~s}^{2}$ ) and wind (green contour; $0.2 \mathrm{~m} \mathrm{~s}^{-1}$ ), and $\mathbf{c}$, $\mathbf{d}$ specific humidity (shade) and saturation specific humidity (contour; $0.05 \mathrm{~g} \mathrm{~kg}^{-1}$ ) along $60^{\circ} \mathrm{E}$ and $80^{\circ} \mathrm{N}$. The blue contour in the upper panel is at $12 \mathrm{~m}^{2} \mathrm{~s}^{2}$. The red contour in the lower panel is at $0.2 \mathrm{~g} \mathrm{~kg}^{-1}$
Figure 4 shows the daily time series of the terms in (9) averaged over the region of sea ice reduction (boxed area in Fig. 1a), and the correlations among individual terms. As can be seen, the net increase in specific humidity in the lower troposphere (1000-850 hPa), on average, is $\sim 1.7 \mathrm{~g} \mathrm{~kg}^{-1}$ (black line) during winter due to sea ice loss. This amount is explained roughly by adding the source term $\left(\sim 1 \mathrm{~g} \mathrm{~kg}^{-1}\right.$; red line) and the horizontal moisture transport $\left(\sim 0.6 \mathrm{~g} \mathrm{~kg}^{-1}\right.$; blue line). Thus, the vertical process plays a stronger role in the net increase of specific humidity in association with Arctic amplification. On the other hand, horizontal moisture transport is significantly correlated with the variation of specific humidity; maximum correlation is 0.588 at lag zero (Fig. 4b). Thus, the variability of specific humidity (not the mean) is strongly controlled by the horizontal advection of moisture. During advection of dry air, net evaporation is increased and vice versa as indicated by the negative correlation between the moisture advection and source terms; correlation is about -0.42 (Fig. 4 b). Thus, the source term tends to moderate the effect of horizontal advection of moisture over the Barents-Kara Seas.

In this calculation, the upper level of significant change in specific humidity is chosen to be $p=850 \mathrm{hPa}$ based on Fig. 2 (see also the vertical profile of anomalous temperature and specific humidity in Fig. S2). Two different choices ( $p=900, p=700 \mathrm{hPa}$ ) of the upper level of integration are also tested and they do not seriously alter the relative importance of the terms in the moisture budget equation (see Figs. S3 and S4).

\subsection{Thermal energy budget}

Figure 5 shows the total greenhouse effect produced by the increased specific humidity. Here, the greenhouse effect is expressed as the net increase in radiative forcing in the atmospheric column, which is primarily due to increased specific humidity. As can be seen in Fig. 5 b, there is a strong correlation $(0.7)$ between the variability of specific 


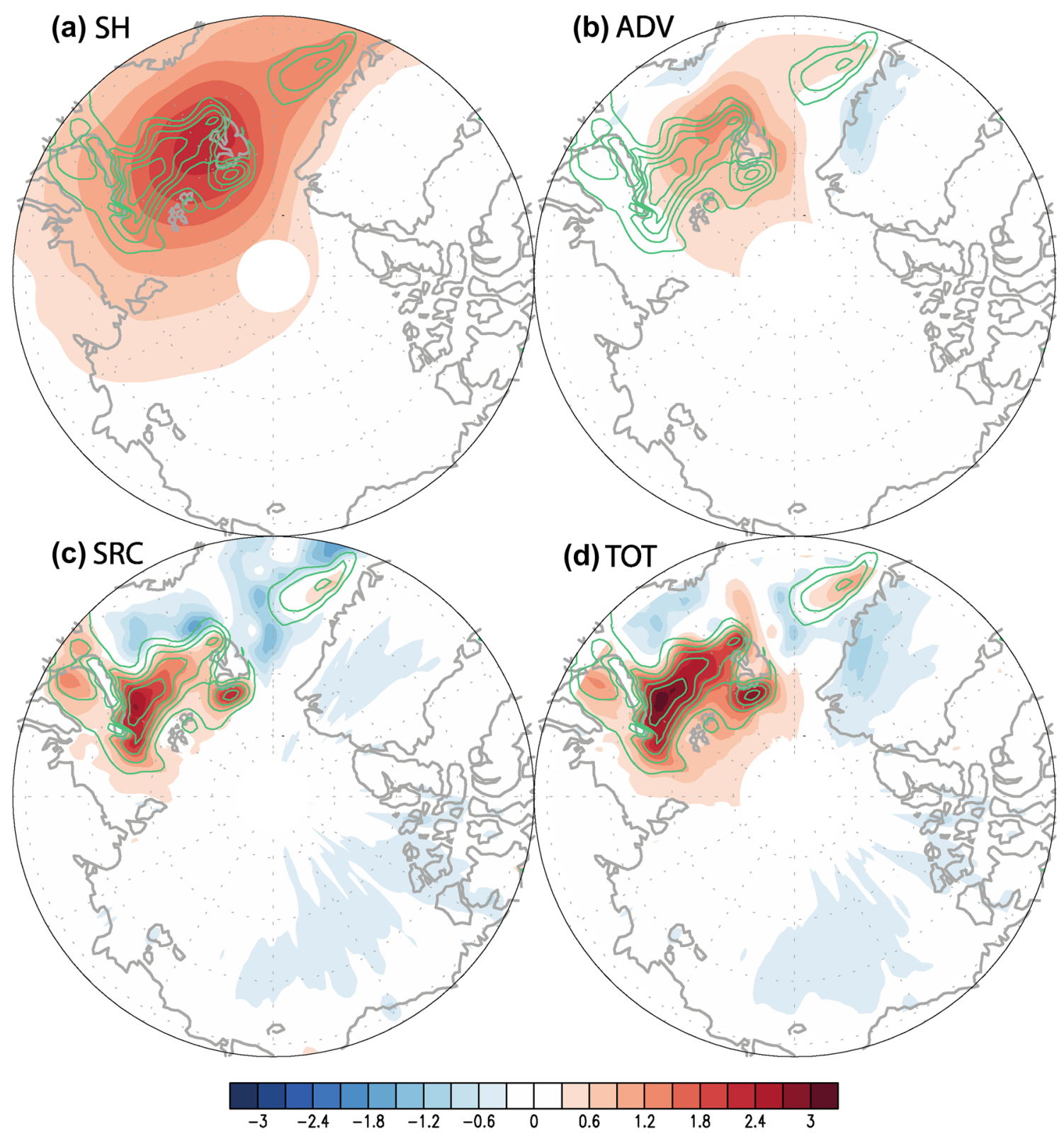

Fig. 3 The winter-averaged lower tropospheric (1000-850 hPa) patterns of variables: a specific humidity, $\mathbf{b}$ moisture advection, $\mathbf{c}$ moisture source (evaporation-precipitation), and $\mathbf{d}$ total (horizontal plus vertical) moisture supply. All the source terms are converted into specific humidity $\left(\mathrm{g} \mathrm{kg}^{-1}\right)$

to the anomalous specific humidity in the vertical column (see Fig. S2). This assumption is partly based on the high correlation between the two variables (Fig. 5b), but is an important caveat in the present study. As can be seen in Fig. 2c, d, increase in specific humidity is mainly confined to the lower troposphere (see also Fig. S2). Therefore, heating due to greenhouse effect should be most conspicuous in the lower troposphere. As seen in Fig. 2a, b, atmospheric warming is also most conspicuous in the lower troposphere. In calculating the contribution from the greenhouse effect to atmospheric warming, we assume that $\sim 62 \%$ of moisture 


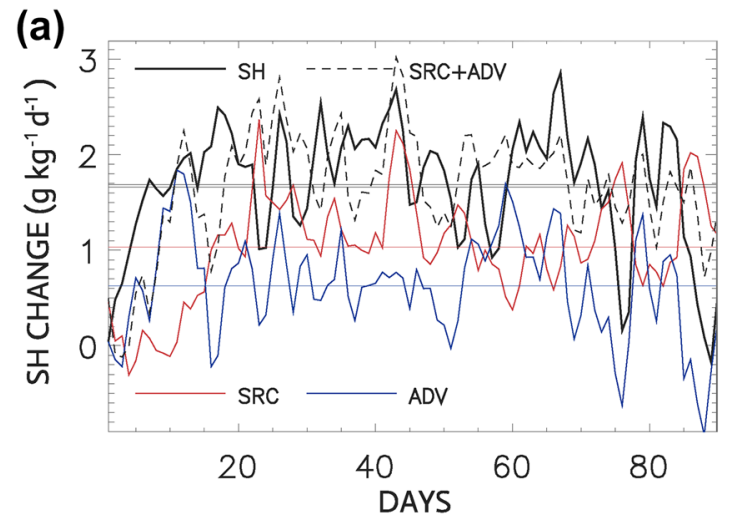

Fig. 4 a Daily fluctuation of $1000-850 \mathrm{hPa}$ averaged specific humidity $(\mathrm{SH})$, evaporation minus precipitation (SRC), and horizontal moisture transport (ADV) averaged over the region of sea ice reduction $\left(21^{\circ}-79.5^{\circ} \mathrm{E}, 75^{\circ}-79.5^{\circ} \mathrm{N}\right)$ in the Barents-Kara Seas (boxed area in Fig. 1a). The straight lines represent the winter means of individual

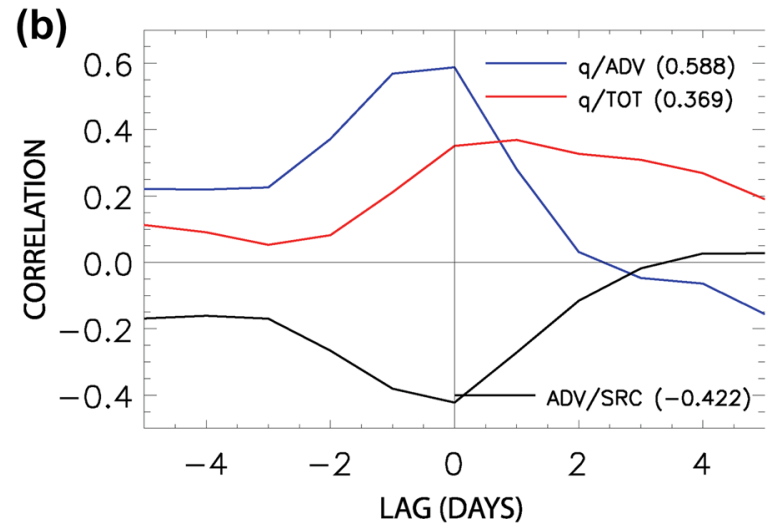

variables. b Lagged correlation between specific humidity and horizontal moisture transport (blue), between the horizontal transport and source (evaporation-precipitation) (black), and between the specific humidity and the total (source plus advection) (red)

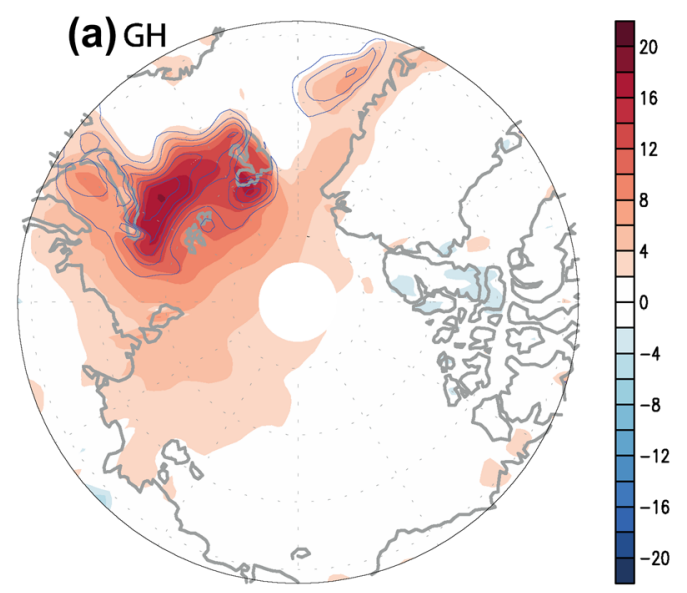

Fig. 5 a The winter-averaged spatial pattern of the greenhouse effect $\left(\mathrm{W} \mathrm{m}^{-2}\right)$. b The daily variation of specific humidity (red) in the lower troposphere (1000-850 hPa) and the greenhouse effect (blue) aver-

increase is from the vertical source and $~ 38 \%$ from the horizontal advection. When the relative roles of vertical source and horizontal advection are estimated, this percentage is taken into account.

Figure 6 shows the terms on the right-hand side of (12). The pattern of the turbulent heat flux indicates that it is strongly tied with the reduction of sea ice in the BarentsKara Seas. The horizontal heat transport and greenhouse effect seem similar in magnitude but are not strictly confined to the region of sea ice reduction. The addition of these three terms and the vertical convection term, which is much smaller than the others, yields the total forcing (converted into temperature) in Fig. 6a. The total forcing term is fairly similar, both in terms of the pattern and magnitude, to the lower-tropospheric temperature increase (Fig. 7). (b)

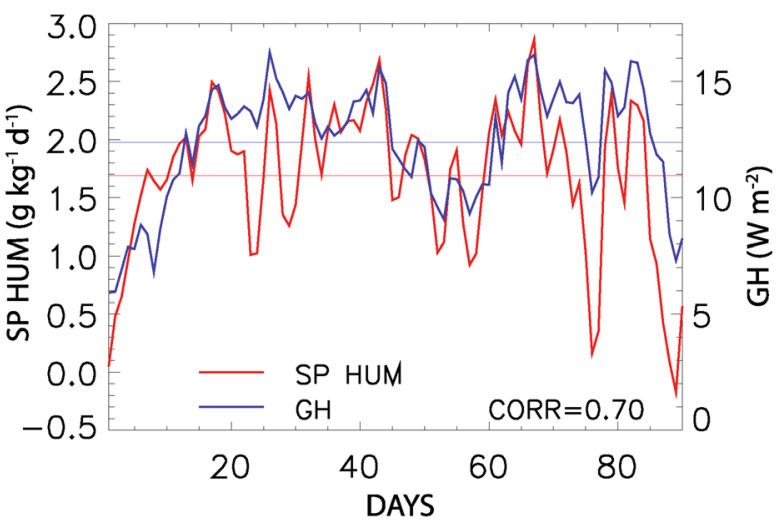

aged over the region of sea ice reduction $\left(21^{\circ}-79.5^{\circ} \mathrm{E}, 75^{\circ}-79.5^{\circ} \mathrm{N}\right)$ in the Barents-Kara Seas

Figure 8 a shows the daily variation of temperature and the heating terms in (12) converted into temperatures averaged over the region of sea ice reduction (see Fig. 1a). As can be seen, the lower tropospheric temperature increased by $\sim 2.1 \mathrm{~K}$ during DJF over the region of sea ice reduction. A little more than $1.04 \mathrm{~K}$ is explained by the turbulent heat flux $(0.68 \mathrm{~K})$ plus $62 \%$ of the greenhouse effect due to increased moisture $(0.36 \mathrm{~K})$. The horizontal advection explains $0.62 \mathrm{~K}$ increase in the lower tropospheric temperature plus $38 \%$ of the greenhouse effect $(0.22 \mathrm{~K})$.

The lagged correlation shows that there is a significant positive correlation between the tropospheric temperature and the heat advection (Fig. 8b). During a warm advection, tropospheric temperature increases and vice versa. It is also apparent that turbulent heat flux decreases during 

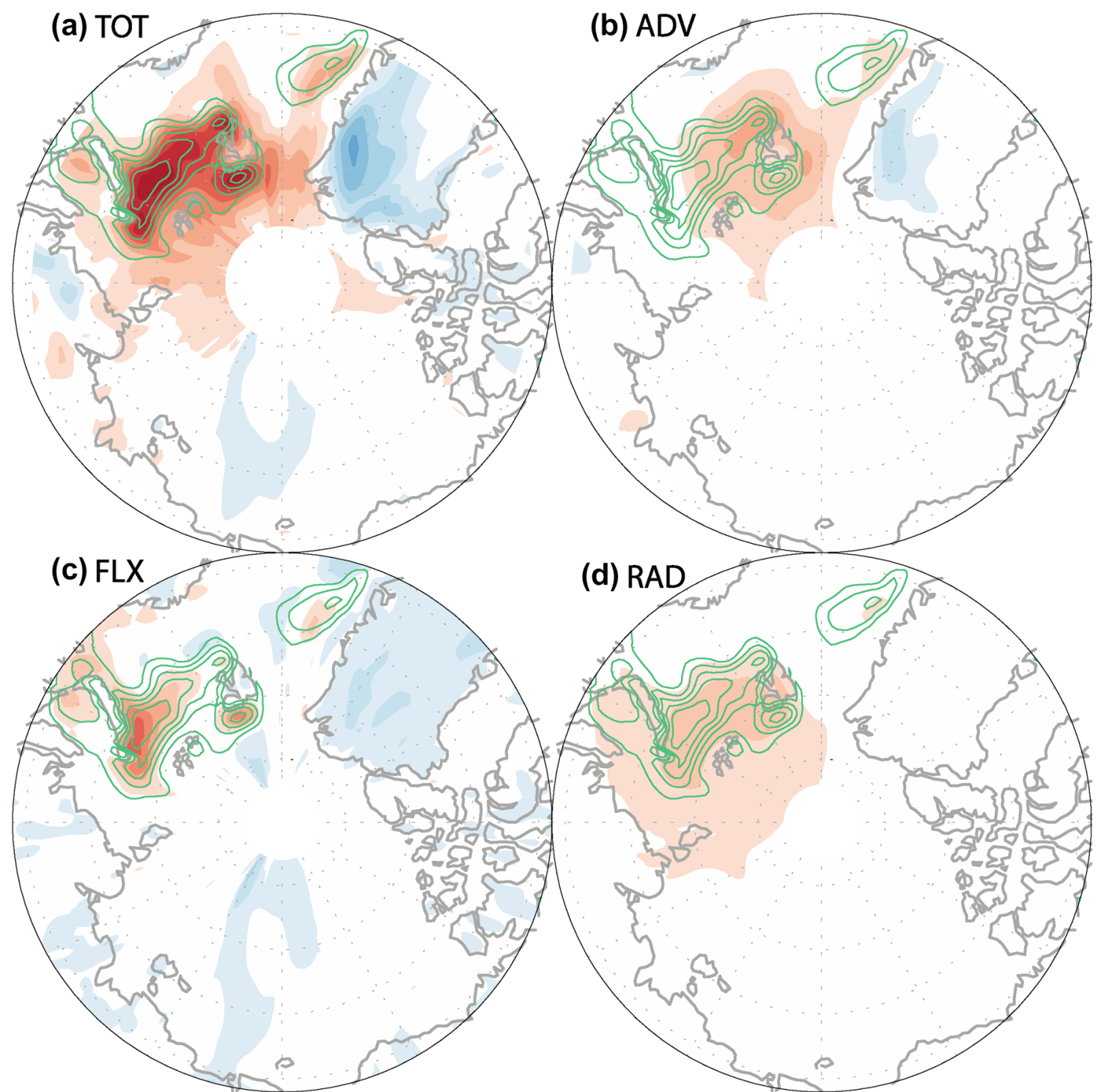

(d) RAD
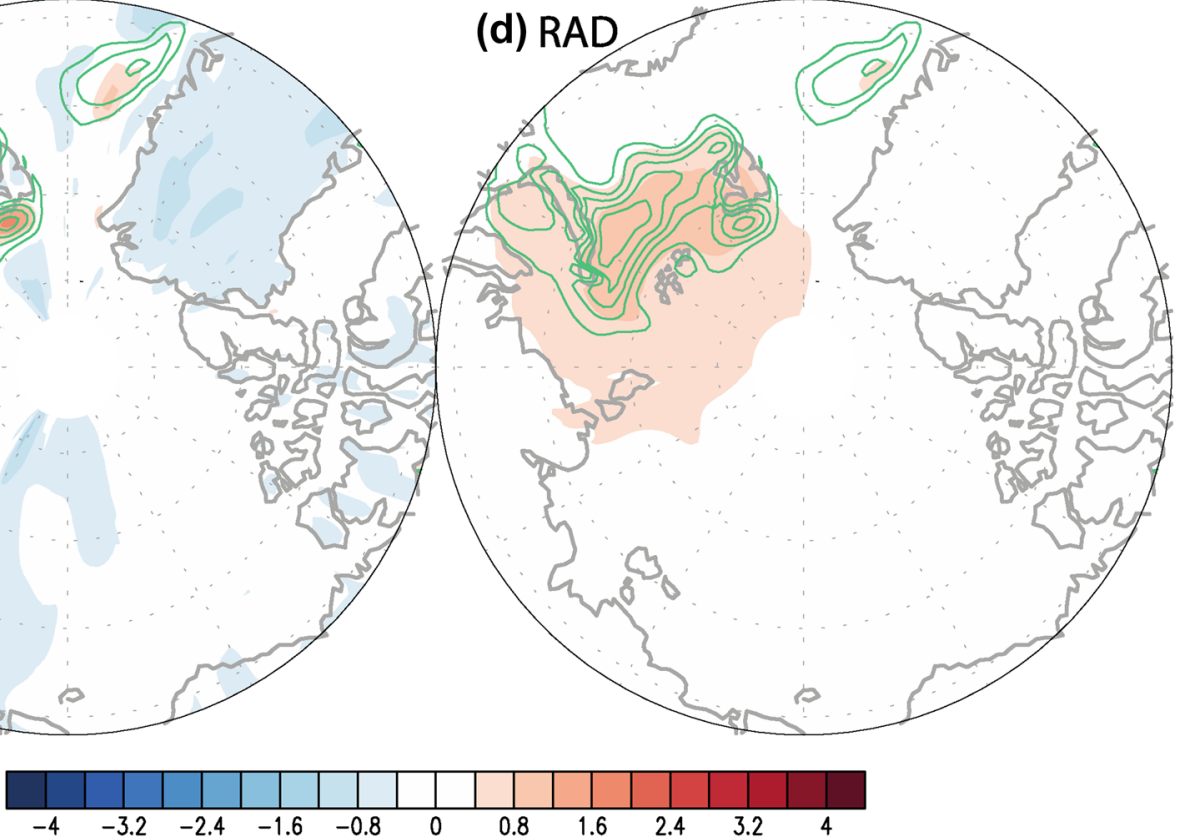

Fig. 6 The winter-averaged lower-tropospheric (1000-850 hPa) patterns of a total heat, $\mathbf{b}$ heat transport, $\mathbf{c}$ turbulent (sensible + latent) heat flux, and $\mathbf{d}$ greenhouse effect. All the terms are converted into temperature anomalies $(\mathrm{K})$

a warm advection and vice versa as indicated by the negative correlation $(-0.552)$ at lag zero. Thus, turbulent heat flux tends to moderate the effect of thermal advection over the region of sea ice reduction. This compensation accomplished by turbulent heat flux, however, is small compared with the thermal advection itself. As a result, the total heating (turbulent flux + horizontal heat transport + greenhouse effect) is still positively correlated with the tropospheric temperature (Fig. 8b). Thus, the horizontal advection of heat is critical in explaining the variability (not the mean) of the tropospheric temperature in association with Arctic amplification. On the other hand, the turbulent flux term, the advection term, and the greenhouse effect make nearly equal contributions to the net atmospheric warming over the Barents-Kara Seas. All three terms are needed to explain $~ 90 \%(\sim 1.9 \mathrm{~K})$ of the lower tropospheric warming.

This situation does not change in any substantial manner depending on the upper pressure levels $(p)$ used for calculating the energy budget. Results by using two different upper pressure levels ( $p=900$ and $p=700 \mathrm{hPa}$ ) are shown in Figs. S5-S7. 

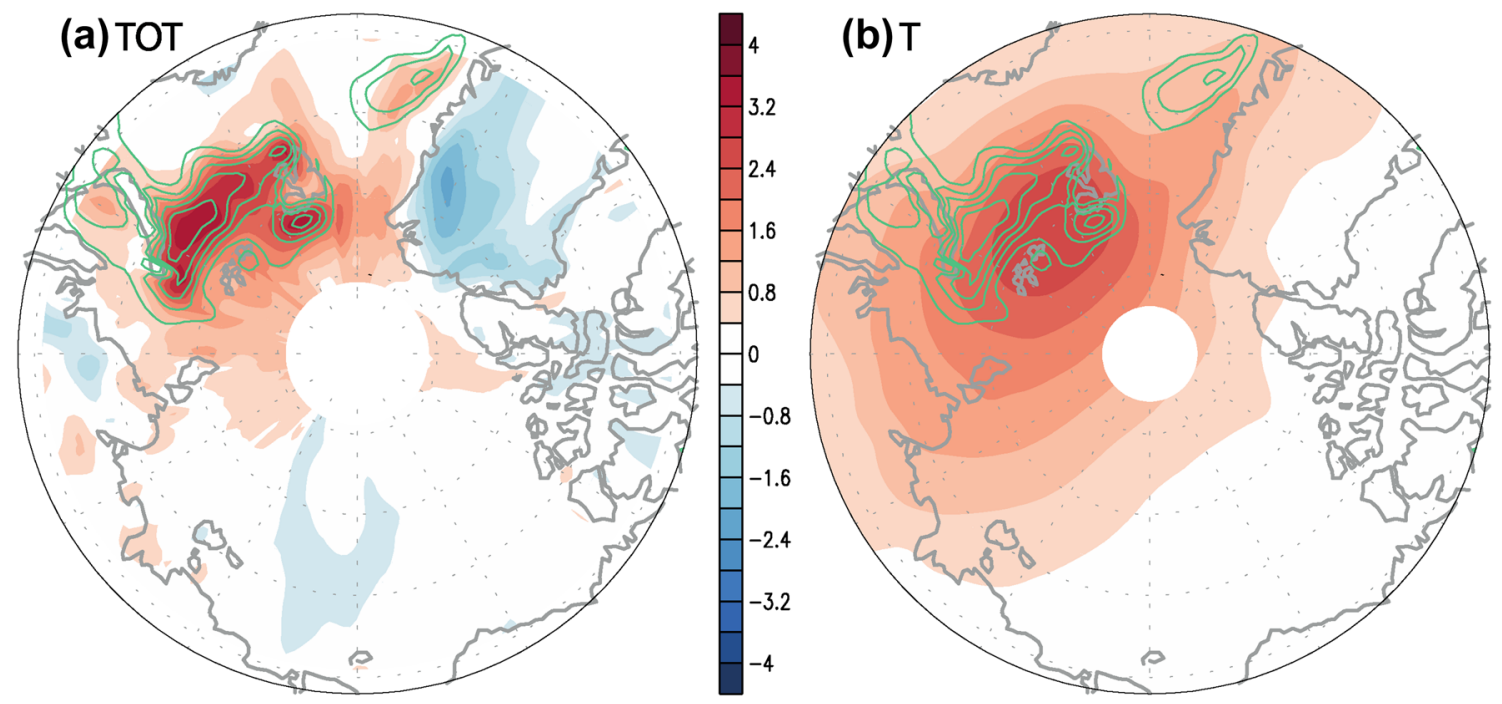

Fig. 7 The winter averaged lower tropospheric (1000-850 hPa) patterns of a total heating converted into temperature, and $\mathbf{b}$ atmospheric temperature

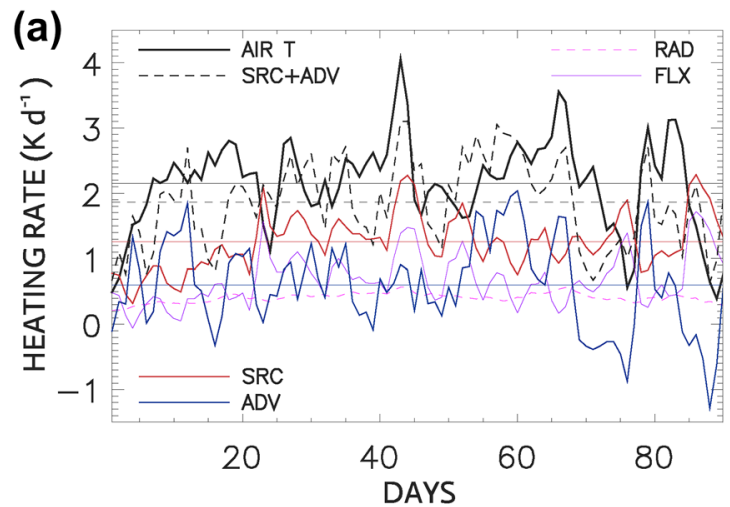

Fig. 8 a Daily fluctuation of $1000-850 \mathrm{hPa}$ averaged temperature (AIR T), turbulent flux (FLX), radiation (RAD), and horizontal heat transport (ADV). The thick red curve is the sum of turbulent flux and radiation (SRC). The straight lines represent the winter means of

\section{Concluding remarks}

Based on the ERA-Interim reanalysis data, detailed heat and moisture budgets are examined in association with Arctic amplification in order to delineate the relative roles of horizontal and vertical processes. The conspicuous warming signal is in the lower troposphere below approximately $700 \mathrm{hPa}$ (see also Fig. S2). Therefore, the analysis results are shown primarily for the lower troposphere (1000-850 hPa).

The moisture budget indicates that about $60 \%$ of the increased moisture derives from the increased evaporation from the region of sea ice reduction. The pattern of

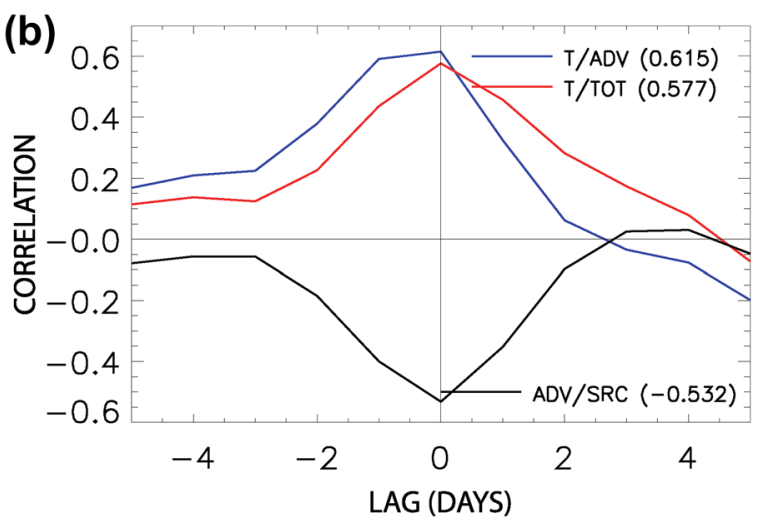

individual variables. b Lagged correlation between temperature and horizontal transport (blue), between the horizontal transport and the other source terms (black), and between the temperature and the total energy

evaporation minus precipitation looks fairly similar to the pattern of sea ice reduction. The bulk of the remaining $40 \%$ is explained by the horizontal moisture advection. While the latter is less effective in explaining the increased specific humidity, it is the primary source of variability of specific humidity in the lower troposphere. The moisture advection is strongly correlated with the variability of the specific humidity over the Barents-Kara Seas. During the advection of humid air, evaporation decreases and vice versa.

The heat budget indicates that temperature increase in the lower troposphere is almost equally partitioned into turbulent flux, horizontal advection and greenhouse effect. Not only the increased turbulent heat flux over the region of 
sea ice reduction but also the increased evaporation plays an important role in Arctic amplification. Specifically, the greenhouse effect produced by the increased specific humidity is comparable in magnitude with that of the increased turbulent heat flux. The increased specific humidity, of course, is a result of moisture source (evaporation minus precipitation) and horizontal advection of moisture as addressed above. Then, the remaining lower tropospheric temperature increase is primarily explained by the horizontal advection of heat. As in the case of moisture budget, the horizontal thermal advection is highly correlated with the lower tropospheric temperature variability. Thus, cold advection results in increased turbulent heat flux and vice versa.

One important caveat in the closure of the heat balance is to quantify the magnitude of the greenhouse effect caused by the increased specific humidity at an arbitrary vertical level. This is accomplished by apportioning the total amount of greenhouse effect in terms of the magnitude of anomalous specific humidity for each level. This obviously is a rough approximation and should eventually be confirmed via a detailed computation using a radiation model.

In conclusion, both the vertical and horizontal processes are needed in explaining the net increase in temperature and specific humidity in association with Arctic amplification. Variability in temperature and specific humidity in the lower troposphere is explained primarily by the horizontal advection of heat and moisture. On the other hand, the vertical source term explains a slightly larger fraction of the mean changes in temperature and specific humidity change than the horizontal advection term. In addition to the role of setting the "net change" in the lower troposphere, the source terms tend to reduce the magnitude of variability caused by horizontal advection of heat and moisture. That is, sensible and latent fluxes increase (decrease) during the advection of cold and dry (warm and humid) air, thereby partially countering the effect of advection.

A limited test using different reanalysis products indicates that the atmospheric response to the sea ice reduction is generally robust and is not overly sensitive to the choice of reanalysis data. It should be borne in mind, however, that uncertainty is inherent in the quantitative estimates in the present study because of the use of a reanalysis product.

Acknowledgements This research was supported by the National Science Foundation of Korea under the Grant no. NRF-2017R1A2B4003930.

Open Access This article is distributed under the terms of the Creative Commons Attribution 4.0 International License (http://creativeco mmons.org/licenses/by/4.0/), which permits unrestricted use, distribution, and reproduction in any medium, provided you give appropriate credit to the original author(s) and the source, provide a link to the Creative Commons license, and indicate if changes were made.

\section{References}

Burt M, Randall D, Branson M (2016) Dark warming. J Clim 29:705719. https://doi.org/10.1175/jcli-d-15-0147.1

Cohen J, Screen JA, Furtado JC, Barlow M, Whittleston D, Coumou D, Francis J, Dethloff K, Entekhabi D, Overland J, Jones J (2014) Recent Arctic amplification and extreme midlatitude weather. Nat Geosci 7:627-637

Dee D et al (2011) The ERA-Interim reanalysis: configuration and performance of the data assimilation system. Q J R Meteor Soc 137:553-597

Deser C, Tomas R, Alexander M, Lawrence D (2010) The seasonal atmospheric response to projected Arctic sea ice loss in the late twenty-first century. J Clim 23:333-351

Francis JA, Hunter E (2006) New insight into the disappearing Arctic sea ice. EOS Trans Am Geophys Union 87:509-511

Iribarne JV, Godson WL (1981) Atmospheric thermodynamics, 2nd edn. D Reidel Publish, Dordrecht

Jakobson E, Vihma T (2010) Atmospheric moisture budget in the Arctic based on the ERA-40 Reanalysis. Int J Climatol 30:2175-2194. https://doi.org/10.1002/joc.2039

Johannessen OM, Kuzmina SI, Bobylev LP, Miles MW (2016) Surface air temperature variability and trends in the Arctic: new amplification assessment and regionalization. Tellus A Dyn Meteorol Oceanogr 68(1):28234. https://doi.org/10.3402/tellu sa.v68.28234

Kim KY, North GR (1997) EOFs of harmonizable cyclostationary processes. J Atmos Sci 54:2416-2427

Kim KY, North GR, Huang J (1996) EOFs of one-dimensional cyclostationary time series: Computations, examples and stochastic modeling. J Atmos Sci 53:1007-1017

Kim KY, Hamlington BD, Na H (2015) Theoretical foundation of cyclostationary EOF analysis for geophysical and climatic variables: concepts and examples. Earth Sci Rev 150:201-218

Kim KY, Hamlington BD, Na H, Kim J (2016) Mechanism of seasonal Arctic sea ice evolution and Arctic amplification. The Cryosphere 10:2191-2202. https://doi.org/10.5194/tc-10-2191-2016

Kurita N (2011) Origin of Arctic water vapor during the icegrowth season. Geophys Res Lett. https://doi.org/10.1029/2010GL046064

North GR, Erukhimova T (2009) Atmospheric thermodynamics. Cambridge Univ Press, Cambridge, pp 267

Overland JE, Wood KR, Wang M (2011) Warm Arctic-cold continents: climate impacts of the newly open Arctic Sea. Polar Res. https:// doi.org/10.3402/polar.v30i0.15787

Park DS, Lee S, Feldstein SB (2015a) Attribution of the recent winter sea-ice decline over the Atlantic sector of the Arctic Ocean. J Clim 28:4027-4033

Park HS, Lee S, Son SW, Feldstein SB, Kosaka Y (2015b) The impact of poleward moisture and sensible heat flux on Arctic winter seaice variability. J Clim 28:5030-5040

Petoukhov V, Semenov V (2010) A link between reduced BarentsKara sea ice and cold winter extremes over northern continents. J Geophys Res 115:D21111. https://doi.org/10.1029/2009jd013568

Ruggieri P, Kucharski F, Buizza R, Ambaum MHP (2017) The transient atmospheric response to a reduction of sea-ice cover in the Barents and Kara Seas. Q J R Meteorol Soc 143:1632-1640. https ://doi.org/10.1002/qj.3034

Screen JA, Simmonds I (2010a) The central role of diminishing sea ice in recent Arctic temperature amplification. Nature 464:1334 1337. https://doi.org/10.1038/nature09051

Screen JA, Simmonds I (2010b) Increasing fall-winter energy loss from the Arctic Ocean and its role in Arctic temperature amplification. Geophys Res Lett 37:L16707. https://doi.org/10.1029/2010G L044136 
Screen JA, Simmonds I, Deser C, Tomas R (2013) The atmospheric response to three decades of observed Arctic sea ice loss. J Clim 26:1230-1248

Sedlar J, Tjernström M, Mauritsen T, Shupe MD, Brooks IM, Persson P, Ola G, Birch CE, Leck C, Sirevaag A, Nicolaus M (2011) A transitioning Arctic surface energy budget: the impacts of solar zenith angle, surface albedo and cloud radiative forcing. Clim Dyn 37:1643-1660

Serreze MC, Barry RG (2011) Processes and impacts of Arctic amplification: a research synthesis. Glob Planet Chang 77:85-96

Serreze MC, Stroeve J (2015) Arctic sea ice trends, variability and implications for seasonal ice forecasting. Phil Trans R Soc A 373:20140159. https://doi.org/10.1098/rsta.2014.0159
Serreze MC, Barrett AP, Stroeve JC, Kindig DN, Holland MM (2009) The emergence of surface-based Arctic amplification. The Cryosphere 3:11-19

Sorokina SA, Li C, Wettstein JJ, Kvamstø NG (2016) Observed atmospheric coupling between Barents Sea ice and the Warm-Arctic Cold-Siberia anomaly pattern. J Clim 29:495-511. https://doi. org/10.1175/JCLI-D-15-0046.1

Yang XY, Yuan X, Ting M (2016) Dynamical link between the Barents-Kara sea ice and the Arctic oscillation. J Clim 29:5103-5122. https://doi.org/10.1175/JCLI-D-15-0669.1 